\title{
Architecture of an Integrated Process Planning and Tool Management System
}

R. Mesquita', E. Henriques ${ }^{2}$, P.S.Ferreira ${ }^{3}$, P.Pinto ${ }^{1}$

${ }^{1}$ INETI - Instituto Nacional de Engenharia e Tecnologia Industrial; Institute of Materials and Production Technology Estrada do Paço do Lumiar; 1699 Lisboa; Portugal;

Tel. 351-1-7165181; Fax. 351-1-7166568

2 IST -Instituto Superior Técnico; Mechanical Engineering Department

Av. Rovisco Pais; 1096 Lisboa Codex; Portugal

Tel. 351-1-8417316; Fax. 351-1-8419058

${ }^{3}$ ITEC - Instituto Tecnológico para a Europa Comunitária; Advanced Manufacturing Technology Centre, Campus INETI;

Estrada do Paço do Lumiar; 1699 Lisboa; Portugal

Tel. 351-1-7165070; Fax. 351-1-7165366

\begin{abstract}
This paper describes the architecture of an integrated system for process planning and tool management, as part of a wider platform comprising all the manufacturing functions. It results from the development of a generative process planning system and a methodology for workplanning and manufacturing resources set-up in a simultaneous engineering environment, using commercial available applications and specially designed interface modules.

The work developed at INETI, IST and ITEC, contributes to the integration of product, process and production planning and aims the increase of productivity, flexibility and consistency of manufacturing processes through the use of information technologies.

The integration of both, a generative and a variant CAPP (Computer Aided Process Planning) system, with a tool management system and a tool pre-setting machine was partially achieved and is presented in this paper. The integrated system is suitable for typical machining job-shops of SME's characterised by small or medium batch production.
\end{abstract}

Keywords

Process planning, tool management, CAPP, production integration 


\section{INTRODUCTION}

During the last years the developments in information technologies allowed the implementation of several forms of Computer Integrated Manufacturing and Engineering (CIME) systems.

With these systems, a new concept of co-operative, concurrent or simultaneous form of task execution has emerged - the simultaneous engineering environment. It was shown in industrial environments the potential benefits of these technologies together with the limitations on the achieved integration of the different engineering and manufacturing functions. In a CIME platform, several functions co-operate from the specification phase until the manufacturing phase, supported by an heterogeneous information network and by distributed applications "aware" of the surrounding environment. However, even in a computer integrated environment, human activity is assisted by non-integrated applications. As a result, typing and printing information are common tasks, performed in order to feed computer aided systems when a high end solution is not available. In a modern flexible jobshop, information promptness and accuracy is vital and making it available just-in-time, where it is needed, is a key factor to build and operate a balanced production system. This is the main goal of the integration effort.

\section{INTEGRATION OF DESIGN, PROCESS PLANNING AND PART PROGRAMMING}

In the last decade several CAD (Computer Aided Design), CAM (Computer Aided Manufacturing) and CAD/CAM systems have been developed. The last ones achieved a considerable degree of integration of the design and manufacturing functions. In order to achieve a full integration, one of the fundamental problems to be solved is the integration of process planning, through the development of a system allowing the automatic generation of process plans starting from a model of the product existing in a CAD database (Chang, 1991; Wang, 1994). Process planning will define the "best" sequence of operations leading to the required quality within the estimated cost and time. Tool selection for each operation plays an important role in this function, particularly when surface quality is critical or when manufacturing productivity varies considerably depending on the tools. Such process plans convey the necessary manufacturing information for the $\mathrm{NC}$ part program generation and should be automatically fed into the CAM system.

The authors developed a prototype of an integrated CAD/CAPP/CAM system (Mesquita, 1993). Some process planning functions were completely automated, such as feature recognition and identification of machining operations (Nunes, 1994), tool selection (Mesquita, 1993) and cutting parameters optimisation (Mesquita, 1995). The work presented in this paper is an extension of this system aiming the integration of process planning and tool management. 


\section{INTEGRATION OF PROCESS PLANNING AND TOOL MANAGEMENT}

Tool selection criteria within CAPP systems are mainly based on the compatibility between tool and machined features, taking into consideration some technological constraints.

Up to now, information management systems concentrated on planning the usage of costly machinery, while tool management played only a minor role. Usually, it is considered that cutting tools are available when and wherever needed. Trends on cutting tools development, leading to increased performance and higher tooling costs - they can reach up to $50 \%$ of the investment in machinery - show the need for an enhanced Tool Management System (TMS).

Tool management functions include, together with the selection of the suitable set of tools, tool list distribution, tool order and inventory control, tool assembly and pre-setting, tool delivery at the workstation and tool tables administration for part program generation and machine tool controller set-up. Increasing the efficiency of tool data handling together with its integration with CAPP systems is an important field of research and development, since it can contribute to maintain the consistency of planned and achieved machining costs and time and to reduce the lead time.

Currently, tool management systems are stand-alone computer aided systems. A considerable management effort is required because of the incompatibility of the various systems. Every tool can be managed by several systems leading to increased error probability, labour intensive data update and increased storage requirements.

Figure 1 presents our concept of an integrated CAPP/TM system, together with the basic relationship with other engineering functions: $\mathrm{CAD}, \mathrm{CAM}$ and $\mathrm{CNC}$ (Computer Numerical Control). The exchange of information supplied by or required by each function is carried out through the job folder.

After the completion of all the tasks related to one job, the job folder is closed and can be used in the shop floor to assist every manufacturing function, from machine-tool setting to part production and control. All the modifications required by the status of the machine-tool will be reflected in the contents of each individual document of the job folder: process plan or route sheet, tool lists, cutting parameters, NC (Numerical Control) part programmes, fixtures drawings and part set-up data.

Considering the target users, composed by SME's, the underlying informatic base system is a low cost system, easily operated and maintained, widely spread and open. We selected a PC network based on a Windows NT server. Industrial PCs (from DLoG) are attached to the machine-tools controllers for DNC (Direct Numerical Control) and monitoring functions. The applications were developed using $\mathrm{C}$ and $\mathrm{C}++$ languages. Commercial $\mathrm{CAD}$ and $\mathrm{CAM}$ systems were used. IGES interfaces enable data import and export from and to the job folder. Both systems offer a programmatic interface, needed to improve the integration level and the degree of automation.

The CAD system is used for part design and fixture design. IGES files containing part geometry information and, when applicable, fixture design data, are exported from the CAD system to be used by the CAPP system for process plan generation. Part drawings and part fixture drawings are stored in the job folder. 

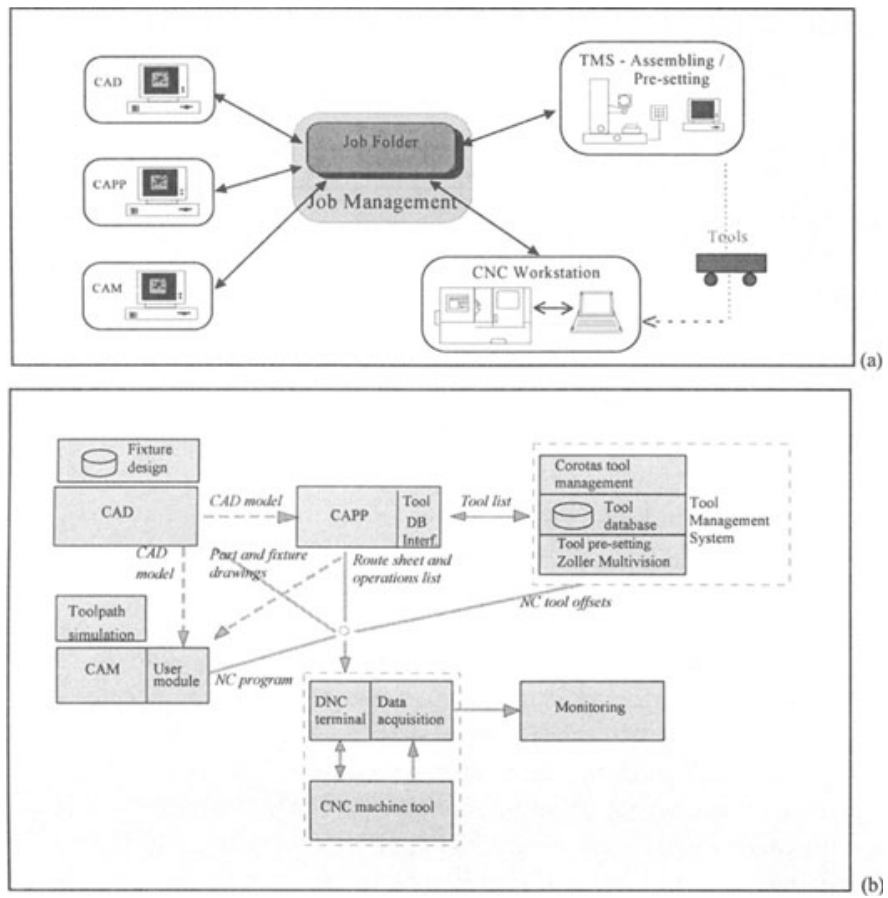

Figure 1 Integrated manufacturing platform (a) and manufacturing document "sourcetarget" flow (b).

The CAM system retrieves from the job folder the part and fixturing IGES files, together with the process plan, operations list and tool list. CNC part programs are generated and archived in the job folder. Depending on the CAM system, process plans and operations list can be used to drive some routines (type of machining, turret position, tool and cutting parameters assignment).

The integration of process planning and tool management can only be accomplished if a central tool database exists. This calls for a tool database standard which is not yet implemented in commercial systems. Consequently, we decided to implement a solution aiming to integrate to some extent the process planning and tool management functions, using totally independent commercially available software applications.

With the purpose to cope with as many operation types as possible, the architecture of our system (figure 2) includes two alternative CAPP systems: MetCAPP/1 and CAPP-TO.

MetCAPP/1 is a general purpose commercial system, of the variant type, developed by IAMS - Institute of Advanced Manufacturing Sciences (Cincinnati, Ohio, USA) and CAPPTO is a generative process planning for turning operations developed by the authors (Mesquita, 1993; Nunes, 1994). Both CAPP systems were integrated with a tool management system (Corotas from Sandvik Automation) which supports all tool related sub-functions tool identification, tool assembly, tool measuring, inventory control. A Zoller V420 Magnum 
tool pre-setter is used for tool measuring. The proprietary measuring programme - Multivision was interfaced with the Corotas package.

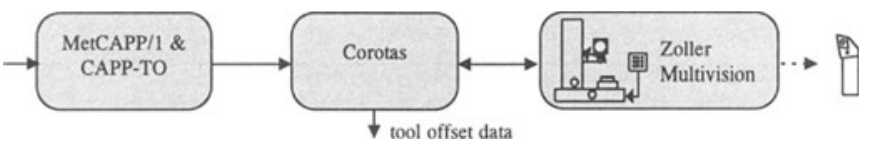

Figure 2 Integrated CAPP/TM system modules.

CAPP-TO is able to generate automatically process plans for turning operations, to optimise tool selection and cutting parameters. Using the part geometrical model as supplied by the CAD system, CAPP-TO produces, with marginal user input, the process plan file (figure 3), operation list files (figure 4) and tool list files.

\section{Figure 3 Process Plan.}

\begin{tabular}{|l|}
\hline Job no. \\
Material \\
Batch size \\
Total manufacturing time $\left(\sum\right.$ set-up time + batch ${ }^{*} \Sigma$ machining time) \\
WSI, Workstation code, Workstation description \\
(..) \\
WSn, Workstation code, Workstation description \\
\hline
\end{tabular}

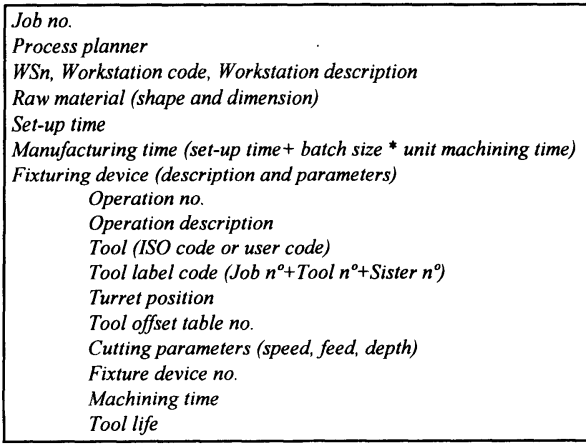

Operations List for workstation Wsn.

The tool lists generated by CAPP-TO convey all the technology-oriented tool data required for tool management in the Corotas system. It is a file formatted as required by the TM system, for data import. Since a common database does not exist, tool data exchange between CAPP system and TMS is performed through import and export functions. A file export facility, specifically designed for Corotas, was built.

Since the MetCAPP/1 system does not allow the exchange of process plan data with other systems, an interface module was developed to extract the relevant data from MetCAPP/1 files. This module formats the tool data according to Corotas requirements and writes the information into an ASCII file. It also creates other files to be used by the CAM system and for the machine-tool operator information. All these files are stored in the job folder. 
Corotas operates at the tool room level together with the pre-setter system. Once Corotas is fed with the tool lists produced by the CAPP systems (one tool list per workstation), the toolkits (a set of tools required to machine a part at a workstation) are defined and the tool items are identified. These tool items are allocated to the job, removed from its stock location and assembled. The assemblies are labelled (with the tool label code) and delivered for measurement and pre-setting at the tool pre-setter workstation.

The link between Corotas and Multivision is already implemented in Corotas. Tool nominal values are send to the tool pre-setter and the tool measured dimensions are returned. After tool measuring, the actual dimensions of the tools are written to a file, which is postprocessed for the particular $\mathrm{CNC}$ controller and stored in the corresponding job folder. The $\mathrm{TM}$ function supplies the job folder with all NC formatted tool offset tables and tool drawings, and provides the workstation with the toolkits, properly identified, for machine setup.

The machine operator has access, through his DNC terminal, to all the information contained in the job folder (figure $1 \mathrm{~b}$ ), when the job manager issues a manufacturing order.

\section{A CASE STUDY}

In order to demonstrate the capabilities of the integrated system, a case study is presented. Figure 5a represents a rotational part geometry as modelled in a CAD system and prepared to be exported via IGES and imported into CAPP-TO.

Through the process planning system graphical user interface the geometrical model is completed, by adding technological features, such as tolerances, surface quality and mechanical or heat-treatments required for the part. Information about workpiece material and raw material type, batch size, and part identification is also included. With some customisation effort in the CAD system, most of this data can be conveyed through the IGES file. Since the system is designed to run on low cost platforms, state-of-the-art computer modelling systems with built-in product-oriented modelling and interfaces (STEP) were not used. If and when these interfaces and standards are introduced in PC-based CAD systems, some of the CAPP-TO feature modelling functions will be discarded.

CAPP-TO automatically selects the sequence of machines / workstations and generates, for turning operations, the sequences of elemental cuts (figure $5 \mathrm{~b}$ ).

For every elemental operation, the system selects the compatible cutting tools, calculates and optimises the cutting conditions and produces both, a process plan, a formatted operations list (figure 6a) and the correspondent data required to drive the Corotas system.

Figure $6 \mathrm{~b}$ presents the results of the detailed toolkit as generated by the Corotas system, together with the merged data collected from the Zoller machine in the tool pre-setting phase (4th and 5th column). This procedure was fully automated and no paper work was required. 

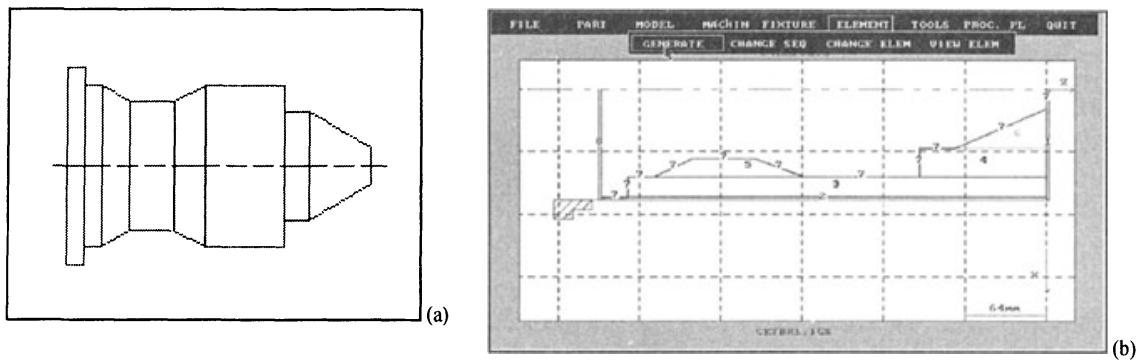

Figure 5 Geometrical model (a) and sequence of operations (b).

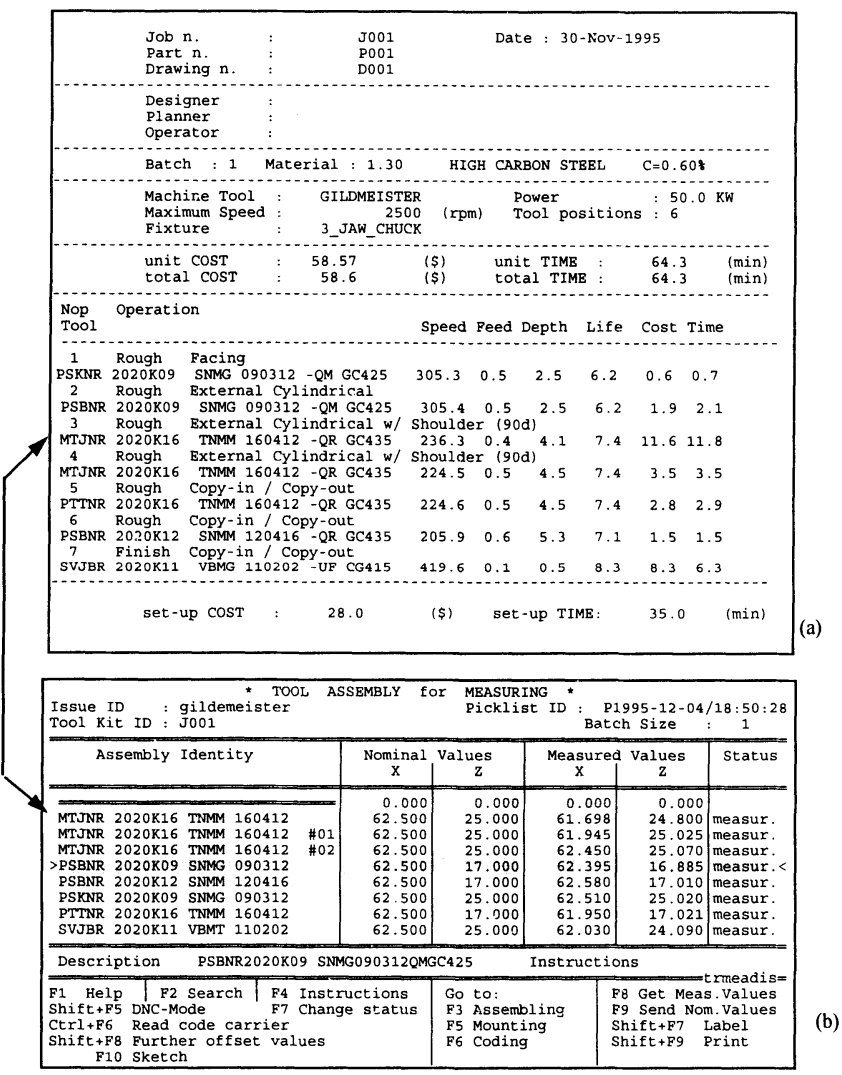

Figure 6 CAPP-TO operations list (a) and Corotas tool list (b).

For example, the third operation in figure $6 \mathrm{~b}$ is an external longitudinal turning operation, constrained by a $90^{\circ}$ shoulder. The CAPP system selects the toolholder MTJNR 2020K16 together with the insert TNMM 160412 -QR GC435 and calculates the cutting parameters, 
operation cost and time (figure 6a). The Zoller system measures the assembly (adapter, toolholder and insert), returning the coordinates $x=61.698 \mathrm{~mm}$ and $z=24.800 \mathrm{~mm}$ to the Corotas system (figure 6b).

The result is stored in the job folder. Each folder has a job identification together with the index of the electronic documents. The documents included are: process plan, operations list, tools list, tools offset table, NC program, drawings (part, tools, fixture devices), manufacturing instructions.

The folder is transmitted to the DNC terminals located at the machine-tools that were identified in the process plan. The machine-tool set-up can be done immediately and production started once the raw material and pre-setted tools arrive at the workstation. No delays due to lack of information or materials occurs.

\section{CONCLUSIONS}

It was presented the architecture of an integrated computer aided process planning and tool management system. The integration of commercial applications supporting design, process planning, tool path programming and tool management requires some interfacing effort. The integration, though restricted, demonstrates some benefits. The generation of consistent and reliable process plans and the conveyance of in-time information lead to less unpredicted events in the shop floor, shorter manufacturing and lead times together with a reduced throughput time, using the same manufacturing resources.

The efficient tool management and the selection of the machine-tool operating parameters, targeting reliable manufacturing and set-up times, contribute, together with the production planning and schedulling, to a balanced production system.

Some additional effort is still required towards the full integration of CAPP and TM systems. In particular, tool selection in the process planning phase must be carried out considering the specific machine-tool and tooling capacities on an underlying dynamic shop floor scenario.

\section{REFERENCES}

Chang, T.C. et al (1991) Computer Aided Manufacturing. Prentice Hall.

Zhang, H.C.and Alting, L. (1994) Computerized Manufacturing Process Planning Systems, Chapman \& Hall.

Mesquita, R.M.D. and Henriques, E. (1993) Modelling and Optimization of Turning Operations. Proc. of the 30th MATADOR Conf., UMIST, Manchester, England.

Nunes, M.C., Henriques, E. M. P.and Mesquita, R.M.D. (1994) Automated Process Planning for Turning Operations. Proc. of the 10th Int. Conf. on Computer-Aided Production Engineering. Palermo, Italy.

Mesquita, R.M.D.and Cukor, G. (1993) An Automatic Tool Selection Module for CAPP Systems. Proc. of the 3rd Int. Conf. on Advanced Manufacturing Systems and Technology. Udine, Italy. 
Mesquita, R.M.D., Krasteva, E. and Doytchinov S. (1995) Computer-Aided Selection of Optimum Machining Parameters in Multipass Turning. Int. Journal of Advanced Manufacturing Technology, vol. 10, 19-26.

\section{BIOGRAPHY}

\section{Professor, Ph.D. Ruy Manuel Dias Mesquita}

received his Ph.D. in Mechanical Engineering at the Technical University of Lisbon in 1988. He his associate professor in Mechanical Technology at IST since 1991. His research activity has been developed in the area of Production Engineering. At present, he is the director of the Institute of Materials and Production Technologies at INETI-National Institute of Engineering and Industrial Technology.

\section{Engineer, M.Sc. Elsa Maria Pires Henriques}

is graduated and received her master degree (M.Sc.) in Mechanical Engineering at the Technical University of Lisbon. Her master thesis was developed in the area of Computer Aided Process Planning. Currently, she lectures Production Management courses at IST and develops a Ph.D. thesis in the area of Dynamic Process Planning.

\section{Engineer, Pedro Manuel Sena Ferreira}

is graduated in Mechanical Engineering at the Technical University of Lisbon. Currently he holds a research assistant position in the Advanced Manufacturing Technologies Centre of ITEC, being involved in development activities in the areas of Computer Aided Process Planning and manufacturing functions integration.

\section{Engineer, Paulo J. Ribeiro Pinto}

is graduated in Electronics and Computer Engineering at the Faculty of Engineering of the University of Porto. He is a research fellow at the Institute of Materials and Production Technologies of INETI. He has participated in several projects in the areas of movement control, process planning and machine-tool monitoring. 